\title{
Recorded Case of Hoffa's Disease without Specific Known Etiology
}

\section{Stéphane Kohpé Kapseu ${ }^{1 *}$, Pamela Mekieje Tumchou², William Youmbi ${ }^{3}$, Kapche Diane², Foko Bebey², Nanko James $^{2}$, Zoyem Meli Patrick², Wona Jean Pierre ${ }^{1}$, Tchangang Yvonne' ${ }^{1}$, Nsangou Adamou ${ }^{2}$, Kuissu Siméon ${ }^{2}$, Tchoukoua Serge Honoré ${ }^{2}$, Ndomgang Noche Christelle ${ }^{1}$, Mandengué Christine ${ }^{2}$, Ossondo Landau Marlène ${ }^{4}$ and Kaptué Lazare ${ }^{2}$}

${ }^{1}$ Surgery Departement, Université des Montagnes, Cameroon

${ }^{2}$ Internal Medecine Departement, Université des Montagnes, Cameroon

${ }^{3}$ Internal Medecine département, Clinic IDIMED, Cameroon

${ }^{4}$ Pathology Departement, Université des Montagnes, Cameroon

*Corresponding Author: Stéphane Kohpé Kapseu, General Surgeon, Cliniques Universitaires des Montagnes, Université des Montagnes, Cameroon.

Received: August 16, 2019; Published: September 12, 2019

DOI: 10.31080/ASMS.2019.03.0406

\begin{abstract}
Hoffa's disease or Hoffite, was first described in 1904 by Albert Hoffa is a benign and a rare pathology. It is defined as an acute or chronic inflammation of infrapatellar fat [1,2]. It is a differential diagnosis of anterior knee pain, which is not obvious because of the absence of specific signs. In many developing countries, the technical platform is limited and patients can not benefit from the universal health care system coverage. We present a case of Hoffa's disease so that practitioners practicing in our context can pay particular attention to cases of chronic gonalgia not responding in to the usual analgesics. Miss B. B. is 19 years old, who consulted for chronic bilateral knee pain without the notion of trauma. An MRI of the knees showed Hoffa disease at the proximal patellar, and sub-quadricipital bursitis with minimal femoro-tibial effusion without meniscal injury. She have had a series of 3 glucocorticoid infiltrations and physiotherapy sessions, which alleviated the pain, and allowed her to fully recover the functioning of her lower limbs. A favorable evolution was observed with a decline in 6 months. Clinical surveillance every 6 months has been instituted. There are many pathologies wich are manifested by pain in the anterior part of the knee. Hoffa's disease, although benign, can be very debilitating. It is important to think of it when faced with chronic gonalgia which is difficult to diagnose and refere the patient to a referal hospital in order to avoid wrong diagnosis.
\end{abstract}

Keywords: Hoffa; Anterior Knee Pain; Corticosteroid Infiltration

\section{Abbreviations}

MRI: Magnetic Resonance Imaging; NSAIDs: Non Steroidal AntiInflammatory Drugs.

\section{Introduction}

Hoffa's disease or Hoffite, was first described in 1904 by Albert Hoffa is a benign and a rare pathology. It is defined as an acute or chronic inflammation of infrapatellar fat [1,2]. It is a differential diagnosis of anterior knee pain, which is not obvious because of the absence of specific signs. In fact, the fat pad of Hoffa, also known as the greasy ball under the patellar, can be the seat of several pathologies such as para-articular chondroma or osteochondroma, pigmented focal villous-nodular synovitis, synovial chondromatosis, lipoma and hemangioma, ganglion cyst and chondrosarcoma [3,4]. In many developing countries, the technical platform is limited and patients do not benefit from the universal health care system coverage. We present a rare case of Hoffa's disease so that practitioners practicing in our context can pay particular attention to cases of chronic gonalgia not responding to the usual analgesics. 


\section{Case Report}

Miss B. B. is a 19 years old, who consulted for a bilateral chronic knee pain without the notion of trauma. The first painful episode occurred 5 years ago before the consultation. The pain which was initially intermittent pain, became paroxysmal in the last seven days prior to her medical visit. Indeed, she complained of a periodic mechanical pain, a partial functional impotence of the lower limbs with knee locking type and a feeling of instability. The latter declared that she can no longer support prolonged standing while waiting for the transport bus. During the physical examination, we noticed a slight valgus, edema of the knees, pain caused by palpating of the edges of the patellar ligament, which was more pronounced to the right. There was no patellar shock. X-rays and ultrasound on both knees were normal. An MRI of the knees showed Hoffa disease located at proximal patellar and sub-quadricipital bursitis with minimal femoro-tibial effusion without meniscal injury (Figure 1). She have had a series of 3 glucocorticoid infiltrations and physiotherapy sessions, which modified the pain, and allowed her to fully recover the functioning of her lower limbs. We observe a favorable evolution with a decline in 6 months. Clinical surveillance every 6 months has been instituted.

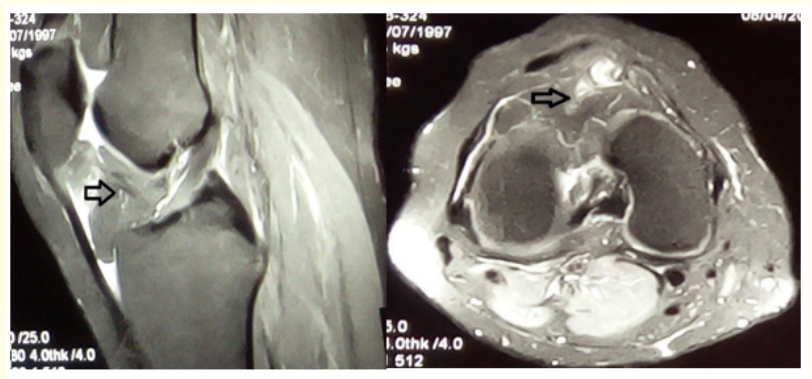

Figure 1: Profil and Axial MRI T2 (arrows showing inhomogen Hoffa's fat).

\section{Discussion}

Hoffa's disease can affect people of all ages. It affects women more than men and concerns mostly young women [1,2]. Age and sex (19 years, female) in our case are mentioned in the literature. There is no unanimity on the mechanisms of occurrence of the disease, but the notion of microtrauma linked to sport physical activity sports (basketball, volleyball, high jump) is frequently mentioned $[1,2,4]$. In our patient, we do not find the practice of a regulary sport activity requiring the knees. There are 2 clinical forms: acute and chronic. The acute phase usually follows a trauma, the clinical picture consists of anterior knee pain, functional, mimicking a ligament injury. As for the chronic phase, concerning our case, one finds recurring hydarthrosis episodes, associated with a reduction of the amplitude of the movements and a discomfort under the patellar [5]. The discomfort is represented in our case by the feeling of instability of which the patient complained. A physical Hoffa test is classically obtained on physical examination. This test performed on a supine patient, hip and knee bent at $90^{\circ}$, is to cause pain during palpation of the lateral and medial edges of the patellar ligament extension of the knee [1]. Hoffa's test was positive in our case. In the chronic phase, ossification of the Hoffa ligament related to fibrosis and scar tissue is an extremely rare pathological entity. When it exists, there is edema or local fibrous thickening, located next to an infrapatellar plica; whereas diffuse edema advocates inflammation of the Hoffa [1-3]. The lack of ossification in our patient, although in the chronic phase, could be related to the effect of not practicing sport actvity which is responsible for microtrauma generating scar tissue in the long run. Morphologically, the x-ray and ultrasound that were normal in our patient have a rather incidental role. In literature review, $\mathrm{x}$-ray analysis allows us to eliminates certain differential diagnosis and shows some patellofemoral dysplasias, considered as a factor favoring Hoffa's disease. It is of interest only during ossified stages. Ultrasound shows the ligament of Hoffa and thus allows the follow up of the disease during the medical treatment. MRI is the test of choice for analyzing Hoffa fat. The axial and sagittal planes adopted in our case, give more information. The most suggestive MRI sign is the presence of significant edema of the infrapatellar adipose body, associated with a fibrous zone that can contain hemosiderin and calcification deposits $[1,2,5]$. Therapeutically, conservative treatment is offered as first-line, base on ice, physiotherapy, oral NSAIDs, more or less associated with immobilization. It may also be recommended to infiltrate corticosteroids in Hoffa fat. In case of failure of failure of a conservative treatment or if Hoffa's disease has become chronic that arthroscopic resection is performed. Arthroscopy is needed for diagnostic and treatment because it allows for a biopsy of inflammatory fatty tissue for histopathological study and later its surgical removal [1]. The option of corticosteroid infiltration for which we have opted is sometimes responsible for fibrous transformation, even calcification of the pathological Hoffa ligament. [2,4,6] Clinical and morphological monitoring, if possible, will allow us to detect an unfavorable evolution. 


\section{Conclusion}

There are many pathologies which are manifested by pain in the anterior part of the knee. Hoffa's disease, although benign, can be very debilitating. It is important to think about it when facing chronic gonalgia that is difficult to diagnose, put it as one of considerable differential diagnosis and to refere the patient to a referal hospital in order to avoid wrong diagnosis.

\section{Bibliography}

1. Larbi A., et al. "Hoffa's disease: A report on 5 cases". Diagnostic and Interventional Imaging 95 (2014): 1079-1084.

2. Boukhris J., et al. "Ossification du ligament de Hoffa : évolution finale de la maladie de Hoffa (à propos d'un cas avec revue de la littérature)". The Pan African Medical Journal 19 (2014): 258.

3. Sivrioglu AK., et al. "A rarely diagnosed cause of anterior knee pain: Hoffa's disease". BMJ Case Report (2013).

4. Sari A and Eroglu A. "An unusual presentation of Hoffa's disease in a middle - age woman with no trauma history: a case report". British Journal of Sport Medicine 50 (2016): A24-A25

5. Morini G., et al. "Hoffa's disease of the adipose pad: magnetic resonance versus surgical findings". Radiology Medicine 95 (1998): 78-85.

\section{Volume 3 Issue 10 October 2019}

(c) All rights are reserved by Stéphane Kohpé Kapseu., et al. 